\title{
ANÁLISES DE POLÍTICAS EDUCACIONAIS REFERENTES AO PROFESSOR DE APOIO EM CLASSES INCLUSIVAS
}

\author{
Danielle Nunes Martins do Prado \\ Celia Regina Vitaliano ${ }^{(*)}$
}

\section{INTRODUÇÃO}

Nos dias atuais tanto se fala em educação para todos, educação inclusiva, escola inclusiva. Esse tema toma conta dos discursos de políticos, gestores e professores.

Para Bueno (2008, p. 31) é o assunto que está na ordem do dia.

A inclusão escolar é, hoje, o tema mais candente do campo educacional em todo o mundo. Isto fica evidente quando constatamos a sua incidência nas grandes propostas políticas nacionais e internacionais, no discurso dos políticos de todos os matizes ideológicos, nas ações concretas dos governantes e de muitas escolas (ou de todas, mesmo que obrigadas), nas produções científicas, acadêmicas e de cunho técnico-profissional. (BUENO, 2008, p. 31).

No entanto, o que é pensar numa educação para todos? Não se trata de uma educação para uma classe homogênea, idealizada e utópica. Mas uma educação que atenda todos, diferentes, com jeitos e necessidades diversas, de modo que tenham seu direito a educação respeitado.

Ao referir-se a esta educação que atenda a todos é imprescindível pensar nas pessoas com NEE, nas políticas públicas voltadas a esta população e nas disposições legais que devem legitimar o direito a educação para todos. Para isso é preciso olhar para as demandas que surgem nesse atendimento. Entre estas, tem emergido a disponibilização do professor de apoio como um dos caminhos para favorecer o atendimento na classe comum dos alunos que apresentam NEE mais comprometidos. Considerando esse fato, oportuno fazer uma análise dos documentos legais, a fim de entender como a legislação educacional apresenta o professor de apoio e o que define em relação a sua atuação numa perspectiva inclusiva.

Tomando como base esta preocupação o presente artigo objetivou: realizar um levantamento das orientações das políticas educacionais nacionais, do estado do Paraná e do município de

\footnotetext{
(*)Danielle Nunes M.Prado. Mestre pela em Educação pela Universidade Estadual de Londrina. Professora dos Anos Iniciais do Ensino Fundamental da Prefeitura Municipal de Londrina, atuando como Apoio do Projeto Político Pedagógico na Secretaria Municipal de Educação de Londrina no Paraná. E-mail: daninunesdoprado @gmail.com. Celia Regina Vitaliano. Docente do Departamento de Educação e do Programa de Pós-graduação em Educação da Universidade Estadual de Londrina E-mail: reginavitaliano@gmail.com.
} 
Londrina em relação ao papel do professor de apoio na classe comum, bem como analisá-las a luz de orientações presentes na literatura especializada sobre o papel desse profissional.

\section{MÉTODO}

Este estudo se constituiu em uma análise documental, pois a busca foi por informações oriundas dos próprios órgãos, sejam eles públicos ou privados.

Pesquisa documental é aquela realizada a partir de documentos, contemporâneos ou retrospectivos, considerados cientificamente autênticos (não fraudados); tem sido largamente utilizada nas ciências sociais, na investigação histórica, a fim de descrever/comparar fatos sociais, estabelecendo suas características ou tendências [...]. (PADUA, 1997, p. 62).

Os documentos analisados foram os documentos legais disponíveis no portal do Ministério da Educação referentes a área de Educação Especial, bem como os documentos disponíveis no portal da Secretaria de Estado da Educação do Paraná e no site da Prefeitura Municipal de Londrina, sendo um deles disponibilizado em material impresso após solicitação ao setor responsável da Secretaria Municipal de Educação de Londrina, visto que não estava no site da mesma. O total dos documentos analisados foram 16, sendo 7 nacionais, 6 estaduais e 3 municipais.

Para analisar os dados tomou-se como base alguns princípios sobre educação inclusiva apresentados nas declarações mundiais que deflagraram a proposta de educação inclusiva, bem como análises presentes na literatura da área especializada que trata da Educação Especial e da Educação Inclusiva.

Quadro 1.Documentos da legislação educacional analisados

\begin{tabular}{|l|}
\hline DOCUMENTOS NACIONAIS: \\
\hline Constituição Federal de 1988 \\
\hline Lei de Diretrizes e Bases da Educação Nacional 9.394/96 \\
\hline Resolução 2 do CNE sobre as Diretrizes Nacionais para a Educação Especial na Ed. Básica de 2001 \\
\hline Política Nacional de Educação Especial na Perspectiva da Educação Inclusiva de 2008 \\
\hline $\begin{array}{l}\text { Nota Técnica - MEC/SEESP/GAB 11/2010: Orientações para a institucionalização da Oferta do } \\
\text { Atendimento Educacional Especializado - AEE em Salas de Recursos Multifuncionais, implantadas nas } \\
\text { escolas regulares }\end{array}$ \\
\hline Lei 13.005/2014. Aprova o Plano Nacional de Educação \\
\hline Lei 13.146/2015. Institui a Lei Brasileira de Inclusão da Pessoa com Deficiência \\
\hline DOCUMENTOS ESTADUAIS \\
\hline $\begin{array}{l}\text { Deliberação 02/03 CEE Fixa as Normas para a Educação Especial na Educação Básica para alunos com } \\
\text { NEE no Estado do Paraná }\end{array}$ \\
\hline $\begin{array}{l}\text { Instrução Normativa 010/08-SUED/SEED. Estabelece critérios para a solicitação de Professor de Apoio } \\
\text { em Sala de Aula }\end{array}$ \\
\hline Instrução Normativa 18/2010 - SUED/SEED: Estabelece critérios para a solicitação de Professor de \\
\hline
\end{tabular}




\begin{tabular}{|c|}
\hline $\begin{array}{l}\text { Apoio em Sala de Aula para atuar com alunos da área dos Transtornos Globais do Desenvolvimento na } \\
\text { Educacão Básica e Educacão de Jovens e Adultos. }\end{array}$ \\
\hline $\begin{array}{l}\text { Instrução Normativa 02/2012 SUED/SEED: Estabelece critérios para a solicitação de Professor de Apoio } \\
\text { à Comunicação Alternativa para atuar no Ensino }\end{array}$ \\
\hline Fundamental, Ensino Médio e Educação de Jovens e Adultos. \\
\hline $\begin{array}{l}\text { Instrução Normativa 04/2012 - SUED/SEED: Estabelece critérios para solicitação de Professor de } \\
\text { Apoio Educacional Especializado na área dos Transtornos Globais do Desenvolvimento na Educação } \\
\text { Básica e Educação de Jovens e Adultos }\end{array}$ \\
\hline $\begin{array}{l}\text { Instrução Normativa 001/2016 - SEED/SUED: Estabelece critérios para a solicitação de Professor de } \\
\text { Apoio Educacional Especializado aos estudantes com Transtorno do Espectro Autista }\end{array}$ \\
\hline DOCUMENTOS MUNICIPAIS: \\
\hline $\begin{array}{l}\text { Deliberação 08/03 CMEL importou a Deliberação 02/03 CEE -PR: Normas para a Educação Especial, } \\
\text { modalidade da Educação Básica para alunos com necessidades educacionais especiais, no Sistema de } \\
\text { Ensino do Estado do Paraná. }\end{array}$ \\
\hline $\begin{array}{l}\text { Instrução Normativa 02/2013 SME Londrina: Regulamenta normas e procedimentos para o Professor de } \\
\text { Apoio Permanente em Sala de Aula do Ensino Fundamental }\end{array}$ \\
\hline $\begin{array}{l}\text { Lei Municipal 12.291/2015 do município de Londrina: Adequa o Plano Municipal de Educação (PME), } \\
\text { instituído pela Lei 11.043, de } 6 \text { de outubro de 2010, às diretrizes, metas e estratégias previstas no Plano } \\
\text { Nacional de Educação (PNE), em conformidade com a Lei Federal 13.005, de } 25 \text { de junho de 2014, e dá } \\
\text { outras providências }\end{array}$ \\
\hline
\end{tabular}

Fonte: dados da autora.

Tais documentos foram analisados sequencialmente, inicialmente os documentos nacionais, na sequência os documentos estaduais e por fim os documentos municipais.

\section{RESULTADOS}

Os dados foram analisados divididos em duas fases: a princípio apresentam-se as análises acerca dos documentos nacionais no que se refere às determinações sobre o professor de apoio, bem como aspectos que o tangencia. A seguir apresentam-se análises acerca dos documentos estaduais e municipais sobre o tema em questão.

\section{ANÁLISE DA LEGISLAÇÃO NACIONAL ACERCA DAS DETERMINAÇÕES SOBRE O PROFESSOR DE APOIO}

A Constituição Federal de 1988 e a Lei de Diretrizes e Bases (LDBEN 9.394/96) são documentos importantes da política educacional do país que inauguram a preferência pelo atendimento dos alunos com NEE no ensino regular, no entanto tais documentos não apresentaram indicações específicas a respeito do tema em questão

Na Resolução 2 de 2001, publicada pelo Ministério da Educação, que estabelece as Diretrizes Nacionais para a Educação Especial na Educação Básica temos a indicação das condições necessárias para a educação de qualidade de todos, incluindo a preocupação em oferecer apoio ao 
professor regente em sala de aula, como evidencia o disposto no artigo $8^{\circ}$ da Resolução 2 de 2001 que determina:

Art. $8^{\circ}$. As escolas da rede regular de ensino devem prever e prover na organização de suas classes comuns:

$[\ldots]$

IV - serviços de apoio pedagógico especializado, realizado, nas classes comuns, mediante:

a) atuação colaborativa de professor especializado em educação especial; (BRASIL, 2001).

Observamos que este artigo, já apontava o que a literatura especializada indica como importante, tendo em vista a educação inclusiva, o trabalho colaborativo entre o professor especialista e os professores das classes comuns, bem como de toda equipe. Díez (2010, p.21) aponta que o modelo de apoio necessário é o modelo colaborativo que não é dirigido apenas ao aluno com NEE, mas também ao professor, a família e a comunidade, a qual considera que "a colaboração entre professorado é fundamental para construir comunidades inclusivas". Esta colaboração, conforme a autora, deve ser entendida como uma forma de trabalhar juntos para resolver os problemas, planejar e organizar a aprendizagem dos alunos.

No ano de 2008 o Ministério da Educação publicou o documento intitulado: Política Nacional de Educação Especial na Perspectiva da Educação Inclusiva. Neste documento tem-se a proposta mais radical de inclusão de todos os alunos na classe comum, cabendo a Educação Especial apoiar esse processo em alguns casos em sala de aula e, principalmente no atendimento educacional especializado (AEE) oferecido no turno inverso.

Cabe aos sistemas de ensino, ao organizar a educação especial na perspectiva da educação inclusiva, disponibilizar as funções de instrutor, tradutor/intérprete de Libras e guia-intérprete, bem como de monitor ou cuidador dos alunos com necessidade de apoio nas atividades de higiene, alimentação, locomoção, entre outras, que exijam auxílio constante no cotidiano escolar (BRASIL, 2008, grifos nossos).

Destacamos que, conforme o referido documento produzido pelo Ministério da Educação, não há referência ao professor de apoio num caráter colaborativo e pedagógico. Equivocadamente o texto propõe para esse profissional funções relacionadas às necessidades básicas.

Harlos, Denari e Orlando (2014) destacam que os profissionais de apoio prestam auxílio aos alunos que não tem independência nas atividades de locomoção, higiene e alimentação e não há referências neste documento quanto à formação e atuação pedagógica que esses profissionais devem ter.

Bem como destaca-se que "não é atribuição do profissional de apoio desenvolver atividades educacionais diferenciadas, ao aluno público-alvo da educação especial, e nem responsabilizar- 
se pelo ensino deste aluno" (BRASIL, 2010 apud HARLOS; DENARI; ORLANDO, 2014, p. 504, grifos nossos).

Outro documento publicado em 2010 pela Secretaria de Educação Especial do Ministério da Educação é a Nota Técnica MEC/SEESP/GAB/ 11/2010 sobre Orientações para a institucionalização da Oferta do Atendimento Educacional Especializado (AEE) em Salas de Recursos Multifuncionais (SRM), implantadas nas escolas regulares. Este documento se insere na análise até aqui realizada, visto que traz em seu bojo uma informação importante, pois ao se referir aos profissionais não docentes da escola regular, cita entre estes o profissional de apoio.

4.3 Profissionais da escola não docentes: número geral de profissionais que não exercem a função docente; formação desses profissionais; carga horária e vínculo de trabalho; função exercida na escola (administrativa, educacional, alimentação, limpeza, apoio ao aluno, tradutor intérprete, guia intérprete, outras). (BRASIL, 2010, grifos nossos).

Esta informação reforça o disposto no documento de 2008 da Política Nacional para a Educação Especial na Perspectiva Inclusiva, que já entendia como não docente o profissional para desempenhar esta função de apoio do aluno com NEE. Contudo, considerando se tratar de um profissional não docente, estes documentos, assim como outros documentos nacionais, não explicitam qual deve ser a sua formação, aspecto importante a ser esclarecido, já que vai atuar no contexto educacional, em sala de aula, num espaço pedagógico, de ensino e aprendizagem.

Cabe destacar que esta determinação sobre a disponibilização do apoio apenas nas condições de locomoção, higiene e alimentação destoa do que a literatura da área tem divulgado no tocante ao trabalho do apoio pedagógico ao aluno com NEE no processo de inclusão escolar. Silva e Maciel (2005) afirmam que o professor de apoio traz a possibilidade de uma resposta educativa mais diversificada que beneficie não somente as crianças com NEE, mas a todas. Para Carvalho (2009) o professor de apoio constitui-se em um interlocutor privilegiado do professor do ensino regular, sendo a colaboração entre os dois, fundamental para o sucesso escolar dos alunos com NEE.

Na mesma direção da determinação dos documentos anteriormente citados (BRASIL, 2008, 2010), temos a Lei 13.005 de 25 de junho de 2014 que estabelece o Plano Nacional de Educação com vigência de 10 anos que cita novamente o termo profissional de apoio em seu texto como uma das metas do Plano Nacional de Educação vigente. A meta $n^{\circ} 4$ trata especificamente da educação especial e faz referência a necessidade do profissional de apoio ou auxiliares, considerando a necessidade de ampliação deste quadro de profissionais, tendo em vista a inclusão escolar. No entanto, novamente este não tem características docentes, não traz orientações nem especifica se é professor, a sua formação e sua atuação. 
Meta 4: universalizar, para a população de quatro a dezessete anos com deficiência, transtornos globais do desenvolvimento e altas habilidades ou superdotação, o acesso à educação básica e ao atendimento educacional especializado, preferencialmente na rede regular de ensino, com a garantia de sistema educacional inclusivo, de salas de recursos multifuncionais, classes, escolas ou serviços especializados, públicos ou conveniados.

Estratégias:

4.13) apoiar a ampliação das equipes de profissionais da educação para atender à demanda do processo de escolarização dos (das) estudantes com deficiência, transtornos globais do desenvolvimento e altas habilidades ou superdotação, garantindo a oferta de professores (as) do atendimento educacional especializado, profissionais de apoio ou auxiliares, tradutores (as) e intérpretes de Libras, guias-intérpretes para surdos-cegos, professores de Libras, prioritariamente surdos, e professores bilíngues; (BRASIL, 2014, grifos nossos).

Mais recentemente, aprovada em 6 de julho de 2015, a Lei 13. 146/2015 institui a Lei Brasileira de Inclusão da Pessoa com Deficiência (Estatuto da Pessoa com Deficiência). Em seu primeiro artigo, aponta que seu objetivo é "assegurar e promover, em condições de igualdade, o exercício dos direitos e das liberdades fundamentais para pessoa com deficiência, visando à sua inclusão social e cidadania."

$\mathrm{O}$ artigo $3^{\circ}$ apresenta alguns itens considerados para a inclusão, como tecnologias assistivas, acessibilidade e entre outros o profissional de apoio escolar entendido como:

XIII. profissional de apoio escolar: pessoa que exerce atividades de alimentação, higiene e locomoção do estudante com deficiência e atua em todas as atividades escolares nas quais se fizer necessária, em todos os níveis e modalidades de ensino, em instituições públicas e privadas, excluídas as técnicas ou os procedimentos identificados com profissões legalmente estabelecidas. (BRASIL, 2015).

Como se observa somente a partir desta Lei 146/2015 referente ao Estatuto da Pessoa com Deficiência é que temos no artigo $3^{\circ}$ a indicação do profissional de apoio atuando nas atividades escolares.

Esta Lei, contempla ainda no capítulo IV os direitos da pessoa com deficiência no que se refere a educação, determinando no artigo 28 que cabe ao poder público acompanhar, avaliar, assegurar e implementar, sistema educacional inclusivo em todos os níveis e modalidades; adoção de medidas de apoio; de práticas pedagógicas inclusivas com formação inicial e continuada de seus professores e; no item XVII, a oferta de profissionais de apoio escolar.

Art. 28. Incumbe ao poder público assegurar, criar, desenvolver, implementar, incentivar, acompanhar e avaliar: 
XI - formação e disponibilização de professores para o atendimento educacional especializado, de tradutores e intérpretes da Libras, de guias intérpretes e de profissionais de apoio;

$[\ldots]$

XVII. oferta de profissionais de apoio escolar (BRASIL, 2015).

Portanto, a partir de um processo lento, porém gradativo, atualmente na legislação educacional nacional há a previsão da presença de profissionais de apoio na classe comum, no entanto, de modo geral, não há orientações a respeito da formação e atuação pedagógica dos mesmos, com ênfase, apenas no atendimento das necessidades básicas dos alunos com NEE, salvo exceção o disposto na Lei 13. 146/2015, já citada.

\section{ANÁLISE DA LEGISLAÇÃO EDUCACIONAL ESTADUAL E MUNICIPAL ACERCA DAS DETERMINAÇÕES SOBRE O PROFESSOR DE APOIO}

Neste ensejo pela inclusão escolar, revisões na legislação educacional própria dos estados da federação se tornaram necessárias. O Estado do Paraná, através do Conselho Estadual de Educação (CEE PR), publicou em 02 de junho de 2003 a Deliberação 02/03 fixando as Normas para a Educação Especial na Educação Básica para alunos com NEE presentes no Sistema de Ensino. Esta norma, além de outras especificações, faz referência ao Professor de Apoio permanente em sala de aula nos artigos 12 e 13 conforme disposto a seguir:

Art. 12 São considerados serviços e apoios pedagógicos especializados os de caráter educacionais diversificados ofertados pela escola regular, para atender às necessidades educacionais especiais do aluno.

Art. 13 Para a escolarização de alunos com necessidades educacionais especiais deverão ser previstos e providos pela mantenedora, quando necessário, os serviços de apoio por:

$[\ldots]$

I. Professor de apoio permanente em sala de aula. (PARANÁ, 2003, grifos nossos).

A Indicação 01/03 desta Deliberação apresenta a caracterização do professor de apoio da seguinte forma:

Professor de apoio permanente em sala de aula: professor habilitado ou especializado em educação especial que presta atendimento educacional ao aluno que necessite de apoios intensos e contínuos, no contexto do ensino regular, auxiliando o professor regente e a equipe técnico-pedagógica da escola. Com este profissional pressupõe-se um atendimento mais individualizado, subsidiado com recursos, técnicos, tecnológicos e/ou materiais, além de códigos e linguagens mais adequadas às diferentes situações de aprendizagem. (PARANÁ, 2003, p. 20). 
Como se observa o texto explicita o termo professor de apoio, diferente do termo "profissional de apoio" utilizado nos documentos nacionais analisados anteriormente, isto de certa forma se configura em um avanço, visto que estabelece claramente para ele uma função pedagógica. No entanto, também identificamos alguns termos que ainda mantém a ideia do trabalho desse profissional restrito a auxiliar o professor regente e realizar um atendimento individualizado ao aluno com NEE. Dessa forma o trabalho desse professor não segue as recomendações, já citadas, de se constituir de modo colaborativo.

Em 2008 o Estado do Paraná editou a Instrução Normativa N.ำ10/08-SUED/SEED que estabelece critérios para a solicitação de Professor de Apoio em Sala de Aula para atuar com alunos com Transtornos Globais do Desenvolvimento no Ensino Fundamental, Ensino Médio e Educação de Jovens e Adultos (PARANÁ, 2008). Neste documento temos avanços na direção de indicar a formação necessária, os alunos que podem receber o serviço e as atribuições desse professor numa perspectiva colaborativa. Esta Normativa também foi utilizada pela Secretaria Municipal de Educação do Município de Londrina para referendar o trabalho do professor de apoio até 2013, data da publicação de sua própria Normativa.

Conforme a referida Instrução Estadual, o Professor de Apoio é definido como profissional de apoio especializado que atua no contexto da sala de aula para atendimento aos alunos com Transtornos Globais do Desenvolvimento (TGD) sendo estes com Autismo, Síndrome do Espectro do Autismo e Psicose Infantil.

Este profisssional deve ter especialização em cursos de Pós-Graduação na área específica; Licenciatura Plena com habilitação em Educação Especial, ou habilitação específica em nível médio e possuir preferencialmente experiência como professor de alunos com TGD. Dentre as atribuições do Professor de Apoio identifica-se pela primeira vez o trabalho colaborativo, bem como em todos os itens há prioridade em relação a aprendizagem acadêmica do aluno apoiado.

3.1.Ter conhecimento prévio e domínio dos conteúdos e temas trabalhados pelo professor da classe comum;

3.2. Participar do planejamento, junto ao professor da classe comum, orientando quanto as adaptações que permitam ao aluno o acesso ao currículo, desde a remoção de barreiras arquitetônicas até às modificações mais significativas na organização da sala de aula, dos materiais e recursos pedagógicos utilizados pelo aluno e pelo professor.

3.3. Promover a interação entre os alunos com Transtornos Globais do Desenvolvimento e os demais alunos da escola.

3.4. Participar das atividades pedagógicas que envolvem o coletivo da Escola.

3.5. Viabilizar a participação efetiva do aluno nas diferentes situações de aprendizagem, a interação no contexto escolar e em atividades extraclasse.

3.6. Buscar diferentes formas que facilitem a interação do aluno no processo de ensino e aprendizagem. 
3.7. Priorizar a necessidade e/ou especificidade de cada aluno, atuando como mediador do processo ensino-aprendizagem com adoção de estratégias funcionais, adaptações, curriculares, metodológicas, dos conteúdos, objetivos, de avaliação, temporalidade e espaço físico, de acordo com as peculiaridades do aluno e com vistas ao progresso global, para potencializar o cognitivo, emocional e social.

3.8. Atuar como um facilitador no apoio à complementação dos conteúdos escolares. (PARANÁ, 2008, grifos nossos).

Após a publicação desta normativa estadual em 2008, outras três instruções normativas foram apresentadas (Instrução Normativa 18/2010 -, Instrução Normativa 02/2012 e Instrução Normativa 04/2012) (PARANÁ, 2010, 2012b) que tratavam dos critérios para a solicitação de Professor de Apoio em Sala de Aula para atuar com alunos da área dos Transtornos Globais do Desenvolvimento na Educação Básica e Educação de Jovens e Adultos e a Instrução 02/2012 - se referia a solicitação de professor de apoio para comunicação alternativa. (PARANÁ, 2012a).

Conforme a Instrução Normativa 001/2016 - SEED/SUED, que revoga a anterior que estava em vigência (Instrução Normativa 04/2012) houve alteração na nomenclatura de professor de professor de apoio para Professor de Apoio Educacional Especializado definido como:

Um profissional com habilitação comprovada para atuar nas instituições de ensino da Educação Básica e na Educação de Jovens e Adultos, da Rede Pública de Ensino do Estado do Paraná, para atender os estudantes com diagnóstico médico de Transtorno do Espectro Autista, com comprovada necessidade relacionada à sua condição de funcionalidade para a escolarização e não relacionada à condição de deficiência, sendo agente de mediação do aprendizado e escolarização. (PARANÁ, 2016, grifos nossos).

Desta maneira, a partir da Instrução Normativa 01/2016 - SUED/SEED, também observamos que o público alvo do professor de apoio educacional especializado foi limitado para os diagnósticos de autismo, visto que o atendimento anteriormente era oferecido aos alunos com diagnóstico de Transtornos Globais do Desenvolvimento, englobando, de maneira mais ampla, os alunos com:

[...] quadro de alterações no desenvolvimento neuropsicomotor, comprometimento nas relações sociais, na comunicação, repertório de interesses e atividades restrito, movimento estereotipado e repetitivo, incluindo neste grupo alunos com Autismo, Síndrome de Asperger, Síndrome de Rett, Síndromes do Espectro do Autismo, Transtorno Desintegrativo da Infância (Psicose Infantil), Transtornos Invasivos sem outra especificação que no geral apresentam dificuldades de adaptação escolar e de aprendizagem, associadas ou não a limitações no processo de desenvolvimento, que dificultam o acompanhamento das atividades curriculares e na sua interação social com colegas e professores, que requeiram apoio e atendimento pedagógico especializado intensos e contínuos. (PARANÁ, 2012b). 
Essa restrição se caracteriza como um retrocesso, pois a Lei 13.146 de 06 de julho de 2015, que estabelece a Lei Brasileira de Inclusão da Pessoa com Deficiência garante o profissional de apoio aos casos:

Art. 2을 Considera-se pessoa com deficiência aquela que tem impedimento de longo prazo de natureza física, mental, intelectual ou sensorial, o qual, em interação com uma ou mais barreiras, pode obstruir sua participação plena e efetiva na sociedade em igualdade de condições com as demais pessoas. (BRASIL, 2015).

Entendemos que há casos de psicoses e outros laudos que necessitam de apoio e com a Instrução Normativa do Estado do Paraná 01/2016 - SEED/SUED vigente, alguns alunos deste estado, deixam de receber este recurso que é necessário para efetivação de sua inclusão na escola regular.

Contudo, importante destacarmos que os itens 3.5, 5.1, 5.2, 5.7 e 5.11 desta Instrução Normativa em vigência reforçam orientações da organização, recursos humanos e atribuições do professor de apoio educacional especializado numa perspectiva colaborativa, vejamos:

2. Organização

$[\ldots]$

3.5. O cronograma de atendimento será elaborado em conjunto com a equipe técnicopedagógica, para orientar os professores das diferentes disciplinas sobre as adaptações/flexibilizações curriculares necessárias que oportunizem ao estudante o acesso à aprendizagem.

$[\ldots]$

5.Atribuições do professor

$[\ldots]$

5.1 Atuar em caráter (intra) itinerante, ou seja, dentro da própria escola, podendo atender a mais de um estudante, ou em diferentes escolas.

5.2 Atuar de forma colaborativa com os professores das diferentes disciplinas, para a definição de estratégias pedagógicas que favoreçam o acesso do estudante ao currículo e sua interação com os colegas, desde a promoção de condições de acessibilidade no contexto escolar até as modificações mais significativas na organização da sala de aula, dos materiais e recursos pedagógicos utilizados pelo estudante e pelo professor.

$[\ldots]$

5.7 Trabalhar com toda a comunidade escolar na perspectiva da inclusão do estudante com Transtorno do Espectro Autista.

$[\ldots]$

5.11 Definir com os professores e equipe técnico-pedagógica procedimentos de avaliação que atendam cada estudante em suas características, interesses, capacidades e necessidades de aprendizagem, acompanhando a evolução de suas potencialidades, com vistas ao progresso global: cognitivo, emocional e social do mesmo. (PARANÁ, 2016, grifos nossos). 
Ainda em relação a atuação do professor de apoio educacional especializado, podemos verificar que referida Instrução reforça o disposto na literatura da área quanto ao cuidado em retirar o aluno de sala de aula ou elaborar atividades que não condizem ao currículo do aluno:

5.8. Ampliar e possibilitar situações de aprendizagem e autonomia sem retirar o estudante para atividades isoladas do contexto da sala de aula.

$[\ldots]$

5.18. É vedado ao Professor de Apoio Educacional Especializado “construir" currículo paralelo em sala de aula, ou seja, trabalhar conteúdos não previstos para o ano ao qual o estudante está matriculado. (PARANÁ, 2016 grifos nossos).

Quanto a participação do professor de apoio educacional especializado na elaboração do Projeto Político Pedagógico, documento norteador e de reflexão das práticas escolares e que deve revelar as condições de inclusão do ambiente escolar, a Instrução Normativa $n^{\circ}$ 01/2016SEED/SUED entende como uma de suas atribuições:

5.10. Participar do Projeto Político-Pedagógico da(s) instituição (instituições) de ensino, assegurando ações e apoios necessários voltados ao atendimento, respeito e valorização da diferença enquanto condição humana e participar dos Conselhos de Classes. (PARANÁ, 2016, grifos nossos).

Os professores de apoio educacional especializado, bem como os professores regentes que têm alunos com NEE em suas classes comuns das escolas regulares, conforme algumas pesquisas (TARTUCI, 2011; CARVALHO, 2009) apontam a formação como uma das necessidades para o atendimento adequado de seus alunos. Destacamos que esse professor precisa ser capacitado para que possa atuar com o professor regente, numa perspectiva colaborativa, a fim de contribuir no processo de aprendizagem de todos os alunos. A Instrução Normativa 01/2016 - SEED/SUED indica que esses professores devem participar de cursos assim como promover estudos com seus pares.

5.12 Participar e organizar grupos de estudos com os professores da instituição de ensino, além de encontros sistemáticos para reflexão, construção e socialização de experiências e de formação continuada promovida pela SEED/DEE. (PARANÁ, 2016, grifos nossos).

Com base nas orientações legais acima elencadas (Lei 9.394/96, Resolução 02/2001 CNE/CEB, Política Nacional de Educação Especial na Perspectiva da Educação Inclusiva de 2008, Deliberação 02/2003 CEE PR), vários sistemas de ensino buscaram caminhos para se adequarem a exigência legal do atendimento dos alunos com NEE no ensino regular. O município de Londrina, considerando as orientações publicadas nos documentos anteriormente analisados. importou a Deliberação Estadual sobre a Educação Especial por meio da Deliberação 08/03 CMEL (Conselho Municipal de Educação de Londrina) e em 2013, estabeleceu a Instrução Normativa 02/2013 que regulamenta normas e procedimentos para o Professor de Apoio Permanente em Sala de Aula do 
Ensino Fundamental. Quanto a definição da função, este documento entende que o professor de apoio permanente:

É um profissional que atua no contexto escolar, nos estabelecimentos do Ensino Fundamental, para atendimento a alunos com deficiência neuropsicomotora acentuada, com graves comprometimentos na comunicação, locomoção e comprometimento nas relações sociais. (LONDRINA, 2013, p. 1).

De acordo com a referida Instrução Normativa é assegurado o Professor de Apoio aos alunos regularmente matriculados na Educação Básica de (EI6 ao $5^{\circ}$ ano) que apresentem as seguintes condições:

[...] da área de deficiências neuropsicomotoras graves (surdez, cegueira, surdocegueira, deficiência física/motora com prejuízo na mobilidade e atividades de vida diária (alimentação, higiene) e na expressão da linguagem oral e escrita, sendo necessário para a sua interação o uso de uma comunicação alternativa e suplementar (outras formas de sinalização e códigos utilizados como meio facilitador do processo ensino-aprendizagem), alterações qualitativas das interações sociais, repertório de interesses e atividades restrito, movimento estereotipado e repetitivo, dificuldades de adaptação escolar e de aprendizagem, associadas ou não a limitações no processo de desenvolvimento, que dificultam o acompanhamento das atividades curriculares e na sua interação social com colegas e professores, que requeiram apoio e atendimento pedagógico intensos e contínuos. (LONDRINA, 2013, p. 2).

Esta Instrução, também aponta as contribuições do professor de apoio nas situações de ensino e aprendizagem e a importância de um trabalho colaborativo com o professor regente da sala. Dentre as suas atribuições, destacamos a primeira:

a) Atuar de forma colaborativa junto ao professor de classe comum, para a definição de estratégias pedagógicas que favoreçam o acesso do aluno ao currículo e sua interação no grupo, desde a promoção de condições de acessibilidade no contexto escolar até as modificações mais significativas na organização da sala de aula, dos materiais e recursos pedagógicos utilizados pelo aluno e pelo professor. (LONDRINA, 2013, p. 2).

Por conseguinte, recentemente foi publicada em Londrina a Lei 12.291, de 23 de junho de 2015 que adequa o Plano Municipal de Educação (PME) ao Plano Nacional de Educação vigente. Em relação a inclusão de alunos com NEE no ensino regular, mais especificadamente no que se refere ao professor de Apoio há previsão na estratégia "4.25 de garantia de profissional para atuar como apoio", ou seja, nesta lei repete-se o disposto no Plano Nacional de Educação (Lei 13.005/2014) fazendo menção ao profissional de apoio e não ao professor. Esse fato se mostra preocupante, visto que parece um retrocesso ao invés de um avanço na garantia de um profissional qualificado para atender os alunos com mais comprometimento. 


\section{CONSIDERAÇÕES FINAIS}

Neste estudo observou-se a dificuldade em encontrar documentos legais, de âmbito nacional, orientadores do trabalho pedagógico do professor de apoio. Em contrapartida, no âmbito estadual e municipal, encontram-se alguns documentos orientadores de um trabalho mais pedagógico e colaborativo deste profissional que deve ser um professor (Resolução 02/03 - CEE PR e Deliberação 08/2003 CMEL, Instruções Normativas 10/08, 18/2010, 02/2012, 04/2012 e 01/2016 SEED/SUED, e a Instrução Normativa SME/Londrina 02/2013).

Para Pereira Neto (2009, p. 57):

[...] a legislação educacional vigente permeou o caminho e contribuiu na configuração do atual cenário em que está inserido o professor de apoio permanente. Em particular, Instruções emitidas pela Secretaria de Educação do Estado do Paraná colaboraram, na medida em que descreveram atribuições a este profissional.

As dificuldades encontradas nos documentos oficiais se refletem no fazer diário escolar. Consideramos de suma importância esclarecer o papel do professor de apoio na legislação, assim como no cotidiano escolar, visto que como destaca Díez (2010), apesar das boas intenções ao estabelecer os serviços de apoio, estes têm se demonstrado insuficientes, inadequados e atuam como mecanismo de segregação e rotulação para os alunos com NEE.

A função do professor de apoio deve ser entendida como um facilitador para que os alunos com NEE estejam de fato incluídos e participantes em todo o processo ensino-aprendizagem. É muito importante que a incorporação à escola da figura do professor de apoio se dê de modo a contribuir efetivamente para inclusão dos alunos com NEE.

Percebemos por meio da cronologia histórica, da legislação educacional e da literatura especializada da área, que o professor de apoio tem sido temática emergente no processo de inclusão escolar e daí a necessidade de aprofundamento da investigação sobre as implicações da ação pedagógica deste professor na inclusão escolar de alunos com NEE. Muito embora às políticas públicas destaquem as suas responsabilidades para o desenvolvimento de práticas pedagógicas inclusivas, ainda o que se vê é que sua atuação, procedimentos e estratégias não têm contribuído para auxiliar a aprendizagem e tão pouco o processo de inclusão escolar. Esta situação em que a sala de aula está dividida entre o professor regente que é responsável e atender os alunos sem NEE e o professor de apoio que é responsável pelos alunos com NEE mantém o modelo segregado de escola. 
No entanto, defendemos que a função do professor de apoio seja entendida como um colaborador com os professores, gestores, família e comunidade para que os alunos com NEE estejam de fato incluídos e participantes em todo o processo ensino-aprendizagem.

\section{REFERÊNCIAS}

BRASIL. Constituição (1988). Constituição da República Federativa do Brasil. Disponível em: <http://www. planalto.gov.br/ccivil_03/constituicao/constituicao.htm>. Acesso em: 23 set. 2016.

Lei 13.005 de 25 de junho de 2014. Aprova o Plano Nacional de Educação - PNE e dá outras providências. Disponível em: <http://www.planalto.gov.br/ccivil_03/_ato2011-2014/2014/lei/l13005.htm>. Acesso em: 23 set. 2016.

Lei 13.146 de 06 de julho de 2015. Institui a Lei Brasileira de Inclusão da Pessoa com Deficiência (Estatuto da Pessoa com Deficiência). Disponível em: <http://www.planalto.gov.br/ccivil_03/_Ato2015-2018/2015/ Lei/L13146. htm>. Acesso em: 23 set. 2016.

Lei 9.394, 20 de dezembro de 1996. Estabelece as diretrizes e bases da educação nacional. Disponível em: <http://www.planalto.gov.br/ccivil_03/leis/L9394.htm〉. Acesso em: 23 set. 2016.

. Ministério da Educação. Nota Técnica - SEESP/GAB/No 11/2010. Orientações para a institucionalização da Oferta do Atendimento Educacional Especializado - AEE em Salas de Recursos Multifuncionais, implantadas nas escolas regulares. Disponível em: <http://portal.mec.gov.br/index.php? option= com_docman\&view= download\& alias=5294-notatecnica-n112010\&category_slug=maio-2010-pdf\&Itemid=30192>. Acesso em: 23 set. 2016.

Ministério da Educação. Política Nacional de Educação Especial na Perspectiva da Educação Inclusiva. Brasília, 2008.

Ministério da Educação. Resolução CNE/CEB No 2, DE 11 de setembro de 2001. Institui Diretrizes Nacionais para a Educação Especial na Educação Básica. Disponível em: <http://portal.mec.gov.br/cne/ arquivos/ pdf/CEB0201.pdf>. Acesso em: 23 set. 2016.

BUENO, José Geraldo. A produção acadêmica sobre inclusão escolar e educação inclusiva. In: MENDES, Enicéia Gonçalves; ALMEIDA, Maria Amélia; HAYASHI, Maria Cristina Piumbato. Temas em educação especial: conhecimentos para fundamental a prática. Araraquara, SP: Junqueira \&Marin; Brasília: CAPES, PROESP, 2008. p. 31-47.

CARVAlHO, Maria Celeste. Professores de apoio educativo: mediadores? Como? Quando? 2009. Dissertação (Mestrado em Ciências da Educação) - Universidade de Lisboa, Lisboa, 2009.

DÍEZ, Anabel Morina. Traçando os mesmos caminhos para o desenvolvimento de uma educação inclusiva. Revista Inclusão: Revista de Educação Especial, Brasília, v. 5, n. 1, p. 16-25, jan./jul. 2010.

HARLOS, Franco Ezequiel; DENARI, Fátima Elisabeth; ORLANDO, Rosimeire Maria. Análise da estrutura organizacional e conceitual da educação especial brasileira (2008-2013). Revista Brasileira de Educação Especial, Marília, v. 20, n. 4, p. 497-512, out./dez. 2014.

LONDRINA. Câmara Municipal. Lei no 11.531, de 9 de abril de 2012. Dispõe sobre o Plano de Cargos, Carreiras e Salários do Magistério Público Municipal do Poder Executivo do Município de Londrina (PCCS do Magistério). Londrina, 2012.

LONDRINA. Câmara Municipal. Lei 12291 de 23 de junho de 2015. Adequa o Plano Municipal de Educação (PME), instituído pela Lei 11.043, de 6 de outubro de 2010, às diretrizes, metas e estratégias previstas no Plano Nacional de Educação (PNE), em conformidade com a Lei Federal nº 13.005, de 25 de junho de 2014. Londrina, 2015.

LONDRINA. Conselho Municipal de Educação. Deliberação nº 08/03. Normas para a Educação Especial no Sistema de Ensino de Londrina. Londrina, 2003.

LONDRINA. Secretaria Municipal de Educação. Instrução Normativa $n^{\circ}$ 02/2013. Regulamenta normas e procedimentos para o Professor de Apoio Permanente em Sala de Aula do Ensino Fundamental. Londrina, 2013.

PÁDUA, Elisabete Matallo Marchezine de. Metodologia da pesquisa: abordagem teórico prática. 2. ed. Campinas: Papiros, 1997.

PARANÁ. Conselho Estadual de Educação. Deliberação no 02/03. Estabelece Normas para a Educação Especial, modalidade da Educação Básica para alunos com necessidades educacionais especiais, no Sistema de Ensino do Estado do Paraná. Curitiba, 2003. 
PARANÁ. Secretaria de Educação. Instrução Normativa n 01/16. Estabelece critérios para a solicitação de Professor de Apoio Educacional Especializado aos estudantes com Transtorno do Espectro Autista. Curitiba, 2016.

Secretaria de Educação. Instrução Normativa 02/12. Estabelece critérios para a solicitação de Professor de Apoio à Comunicação Alternativa para atuar no Ensino Fundamental, Ensino Médio e Educação de Jovens e Adultos. Curitiba, 2012a.

Secretaria de Educação. Instrução Normativa 04/12. Estabelece critérios para a solicitação de Professor de Apoio em Sala de Aula para atuar com alunos com Transtornos Globais do Desenvolvimento no Ensino Fundamental, Ensino Médio e Educação de Jovens e Adultos. Curitiba, 2012b.

Secretaria de Educação. Instrução Normativa 10/08. Estabelece critérios para a solicitação de Professor de Apoio em Sala de Aula para atuar com alunos com Transtornos Globais do Desenvolvimento no Ensino Fundamental, Ensino Médio e Educação de Jovens e Adultos. Curitiba, 2008.

Secretaria de Educação. Instrução Normativa 18/10. Estabelece critérios para a solicitação de Professor de Apoio em Sala de Aula para atuar com alunos com Transtornos Globais do Desenvolvimento no Ensino Fundamental, Ensino Médio e Educação de Jovens e Adultos. Curitiba, 2010.

PEREIRA NETO, Eloi Alexandre. A ambivalência do papel do professor de apoio permanente em salas regulares do ensino fundamental. 2009. Trabalho de Conclusão do Curso (Graduação em Pedagogia) - Universidade Estadual de Londrina, Londrina, 2009.

SILVA, Karla F. W.; MACIEL, Rosângela Von M. Inclusão escolar e a necessidade de serviços de apoio: como fazer? Centro de Educação da UFSM/RS. Revista Educação Especial, Santa Maria, n. 26, 2005.

Dulcéria. Professor de apoio, seu papel e sua atuação na escolarização de estudantes com necessidades educacionais especiais em Goiás. In: CONGRESSO MULTIDISCIPLINAR DE EDUCAÇÃO ESPECIAL, 7., 2011, Londrina. Anais... Londrina, 2011.

\section{RESUMO}

O processo de inclusão escolar de alunos com necessidades educacionais especiais fez surgir a figura do professor de apoio. Este artigo analisa as orientações das políticas educacionais nacionais, do estado do Paraná e do município de Londrina acerca do papel desse professor. Foram analisados dezesseis documentos legais, considerando o papel do professor de apoio no contexto da educação inclusiva. Os resultados evidenciaram que a legislação educacional nacional, na maioria dos documentos contempla um profissional com funções voltadas à locomoção, higiene e alimentação. As legislações educacionais do estado do Paraná e do município de Londrina orientam quanto a uma prática colaborativa do professor de apoio junto ao professor regente de classe comum numa perspectiva inclusiva.

Palavras-chave: políticas educacionais, educação inclusiva, professor de apoio.

\section{Analyzes of educational policies regarding support teacher in inclusive classes \\ ABSTRACT}

The process of scholar inclusion with special educational needs gave rise to the figure of the support teacher. This article analyzes the orientations of the national educational policies, of the state of Paraná and the city of Londrina about the role of those support teachers. Sixteen legal documents were analyzed, considering the role of the support teachers in the inclusive educational context. The results showed that the National education legislation, in the majority of the documents it contemplates a professional with functions oriented to the locomotion, hygiene and alimentation. The educational legislation of the state of Paraná and the city of Londrina conduct to a collaborative practice of the support teacher with common class teacher in an inclusive perspective

Keywords: Educational policies; inclusive education; support teacher. 